\title{
Taking on the heat-a narrative account of how infrared cameras invite instant inquiry
}

Jesper Haglund, Fredrik Jeppsson, \& Konrad J. Schönborn

\section{Postprint}

N.B.: When citing this work, please cite the original article.

Original Publication:

Haglund, J., Jeppsson, F., \& Schönborn, K.J. (2015). Taking on the heat-a narrative account of how infrared cameras invite instant inquiry. Research in Science Education. Advance online publication. doi: 10.1007/s11165-015-9476-8

http://dx.doi.org/10.1007/s11165-015-9476-8

Copyright: Springer 


\section{Taking on the heat - a narrative account of how infrared cameras invite instant inquiry}

\section{Introduction}

We are confronted with a series of challenges in science education in the western world, which reflect the overall development of society. For one, international standard tests such as TIMSS and PISA on students' literacy and proficiency in different school subjects, including science, show that our children do not learn as much as we would have hoped and expected in our educational systems. In addition, international surveys, such as ROSE (Sjøberg and Schreiner 2005), show that students' interest in school science is low in general. This reveals shortcomings in the way we teach subjects, and a lack of relevance in relation to students' everyday life and society. We start this paper by laying down some potential trajectories in how to take on these challenges.

First, we see a great opportunity in the exploitation of technology for educational purposes. In science education, this opportunity transcends the mere use of social media, standard wordprocessing and spreadsheet programs, and searching for information on the Internet. Particularly interesting developments in technology include tools for real-time data collection and representation, modelling and simulation (Linn 2003). Such technology enables phenomena that are too small, too large, too fast or too complex to be seen by the naked eye, thus making the invisible visible.

Second, we would advocate full use of the social environment of the classroom. As theorised by prominent scholars of educational science (e.g. Wood et al. 1976; Piaget 1932; Vygotsky 1978), students will learn more through interaction with teachers and peers than they are able to independently. In particular, collaborative interaction in small groups provides an opportunity for students to share their ideas and assume ownership of their own learning, driven by their curiosity rather than prescription, which has been found to be more effective for learning than individual or competitive approaches (Johnson et al. 1981; Okebukola and Ogunniyi 1984). Similarly, in relation to conceptual understanding of mechanics (Hake 1998), interactive teaching approaches to physics education have been found to lead to higher learning gains than traditional approaches that are based on one-way communication and “cookbook” laboratory exercises.

Third, in order for students to build a coherent understanding of different science domains, the introduction of a set of scientific models is needed (Lehrer and Schauble 2006; Gilbert 2004). These models should be appropriate for the particular age group in focus, and robust enough to provide productive "stepping-stones" for students' learning progression. An example in case is the use of a simple heat-flow model in order to introduce the idea that heat flows from objects of higher temperature to objects of lower temperature (Linn and Eylon 2011; Arnold and Millar 1996; Rosebery et al. 2010). Such a model may help students disambiguate heat and temperature, and relate these concepts to their own experiences. The heat-flow model may subsequently serve as a starting point for the introduction of more advanced, microscopic accounts of thermal phenomena.

In identifying the above three trends, and in particular considering how they may converge in the teaching of thermal science, we see the Knowledge Integration framework, developed by Marcia Linn and colleagues (e.g. Linn and Eylon 2011), as a sound foundation for building and pointing out important aspects of the future of science education research and practice.

The present study is framed within an exploration of the potential of applying hand-held infrared (IR) cameras in the learning of thermal science in two Swedish fourth-grade classes 
with 9- to 11-year-old pupils. The teaching intervention involved a curricular-based storyline that targeted concepts such as heat, temperature, thermal equilibrium, heat conduction and insulation, as well as building an awareness of energy challenges and global warming, by means of introducing a heat-flow model. In particular, we follow a group of pupils as they interact collaboratively with a hands-on IR-camera based laboratory task, based on a predictobserve-explain (POE) approach (White and Gunstone 1992). We provide a narrative thick description (Geertz 1973) of the pupils' interaction with the laboratory equipment, each other and one of the researchers $(\mathrm{JH})$ in the role of a facilitator. Unfolding as four chronological episodes, we bring across and analyse how the children investigate what occurs when they pour warm water into a coffee mug and a thin plastic cup, respectively. Which will get warmest? Against this background, the following two research questions were posed in the study:

- How can IR cameras inspire sustained observation and instant inquiry in a fourthgrade small-group laboratory exercise on heat?

- What conceptions and conceptual challenges are expressed among a small group of fourth-graders in a laboratory exercise on heat by use of IR cameras?

\section{Children's Conceptual Understanding and Teaching of Heat and Temperature}

Piaget and Garcia (1977) conducted interviews with children of different ages in relation to simple experiments in order to study their ideas of heat. The experiments included heating a steel ball and dipping it in cold water, and heating the end of an aluminium strip causing a piece of wax to melt at the other end. They found that the idea of heat as transmission or passing from or through a warm object to a colder object developed relatively late. In stages I (typically up to 7 years old) and II (7-11 years old), the children entertained ideas of heat as 'contagious action', where a warm object heats up a colder object without being cooled down itself, or an exchange of heat without considering equalisation. Piaget and Garcia (1977, p. 102) succinctly conclude: "Only in stage III is conduction understood" (1977). Overall, they identified that children's ability to provide causal explanations of heat is delayed by one developmental stage, compared to explanations of transmission in mechanical phenomena, which they attributed to the limited opportunities to engage and coordinate physical manipulation and vision.

Adhering to a Piagetian tradition, Shayer and Wylam (1981) studied 9-13 year old pupils' conceptions of heat and temperature by means of test items related to seven experimental setups, including the ones reported by Piaget and Garcia (1977). They found the majority of the studied pupils to be in the late concrete stage (2B), where they conceptualised heat causally as involved in heating things up, but without differentiating the extensive heat and the intensive temperature. In line with Piaget and Garcia's findings, only a minority of the pupils - and apparently none in the youngest age group, 9/10 year olds - had reached the early formal stage (3A), where they had developed the idea of heat as an extensive quantity, an entity that flows from a warm to a colder object. In turn, very few of these offered particlebased, kinetic theory explanations of heat, but rather engaged caloric-like ideas of conduction of heat as a fluid flow.

With the constructivist wave in science education prominent in the latter part of the twentieth century, the Piagetian programme of establishing content-independent stages of children's intellectual development gave way to an interest in the specific conditions of learning in different domains. In particular, scholars such as Erickson (1985) and Tiberghien (1985) took an interest in students' learning in the thermal domain. In contrast to Piaget and Garcia (1977) and Shayer and Wylam (1981), in an overview of research on pupils' conceptions of 
heat and temperature, particularly his own interviews with 5-13 year old children, Erickson (1985, p. 58) concluded that "pupils of all ages rapidly refer to the 'transfer of heat' from one object to another" in experiments such as heating a metal rod at one end with a candle. However, they often do so without talking of heat as a noun, but rather in terms of a process of one object heating another. In addition, he found it difficult for children to deal with the situation of touching objects of different materials at room temperature. Children typically attribute $a d$ hoc inherent properties to the materials, such as metals feeling cold due to their ability to "attract" cold, or just as a matter of fact. As a reaction to such challenges, Erickson (1985, p. 59) proposes:

If pupils were able to 'see' this phenomenon [that metals feel cold at room temperature] in terms of a transfer of energy from their body to the object, this sort of situation would likely be less of a problem than it seems to be at present.

The difficulty in accounting for why metals feel colder than many other materials at room temperature also extends to older learners. Engel Clough and Driver (1985) found 12-16 year olds to have challenges explaining why a metal plate feels cooler than a plastic plate at room temperature. In contrast, however, the participants were much more successful at justifying why a wooden or plastic spoon placed in hot water does not burn your hand when you touch it while a metal spoon does, by reference to heat transfer. Engel Clough and Driver (1985, p. 181) conclude: "quite simply students find it difficult to think of conduction of heat when they feel cold". Lewis and Linn (1994) investigated conceptions of heat and temperature among eighth-graders, non-specialist adults and natural scientists. When the non-specialist adults were given objects of different materials, some of which felt colder than others but actually had the same temperature, several of them even questioned the accuracy of the mercury or digital thermometers used. Overall, they relied on the belief (although misleadingly) that their sense of touch is a dependable thermometer.

Howe (1998) interviewed 6-15 year old children regarding their conceptions of different physical phenomena, including heat transfer. Assisted by photographs of the scene, she asked the children to argue for which pan (from a selection of four) is best for heating water on a cooker, and which fork (out of four) would prevent a cook from being burnt while cooking. Howe found that thin walls and the material being metal were conceived as the most common favourable factors for heat transfer through the pan, whereas the cook would not get burned if long and non-metal forks were used, all adequate factors. However, only a minority of the children provided explanations of heat conduction in terms of transmission through the pans or forks. In support of Piaget and Garcia (1977), there is a clear age trend where the two older groups (12-13 and 14-15 year olds) employed the idea of heat transmission more than the younger children (up to 10-11 year olds). In relation to this and related research, Howe (1998, p. 61) concludes: "The improvement can be characterised as a 'big leap forward' between 10 and $12 "$.

Howe and colleagues have also investigated the impact of critical testing on children's understanding in collaborative small-group work on heat transfer. Howe et al. (1995) allowed children of age 8-12 years to collaborate in groups of four while experimentally investigating the cooling of hot water in different containers, varying in different respects, such as material and thickness. In posttests that followed pretests, the children referred significantly more to the thickness and surface area of the containers. In addition, the condition of using critical tests, i.e. comparing pairs of containers that differed only in one variable, in combination with rule generation, i.e. writing down factors that are relevant to how quickly hot water cools down, was found to lead to better explanations of the processes of heating and cooling, compared to when one or both of these approaches was not followed. Using a similar collaborative experimental study, Howe and Tolmie (2003) studied children's predictions of 
which of two containers containing hot water would cool down quickest and their explanations of which factors were important to consider, e.g. thickness or material, followed by devising critical tests of these explanations, assisted by the one of the researchers. They found that instructing the children to reach a consensus on the predictions and explanations before moving on to the critical tests was crucial for the children to improve their conceptual understanding of the phenomenon.

When it comes to teaching about thermal phenomena, Tiberghien (1985) reports on her teaching of 10-14 year old pupils. Prior to teaching, the pupils typically provide explanations of heat conduction by relating to properties of the materials, for example they become more or less easily hot or are better or worse at retaining warmth, but rarely talk of heat transfer or interaction between objects. In response to such ideas, Tiberghien designed teaching centred on the ideas that heat transfers from a point of higher temperature to one of lower temperature, and that different materials conduct heat more or less effectively (conductors and isolators, respectively). Similarly, recognising the difficulty for pupils to view heat in terms of energy transfer, Arnold and Millar (1996) adopted the approach of using the term 'heat' as something that is stored in and flows between warm objects, i.e. in line with the caloric theory of heat which was otherwise abandoned by scientists with the introduction of the energy concept. With this approach, they developed a teaching sequence that focused on a story about the interrelationship between the concepts of 'temperature', 'heat' and 'thermal equilibrium'. Along the same lines, in the development of the Knowledge Integration framework, Linn and colleagues (e.g. Linn and Eylon 2011) began with microscopic approaches to grade 8 thermal science, but later chose to rely primarily on a macroscopic heat-flow model following some years of the program.

Rosebery, Ogonowski, DiSchino and Warren (2010) present impressive learning results from a design experiment conducted with a combined class of third- and fourth-graders, that involved the content of heat and a particle account of matter. Early on, the children were introduced to a poster stating the second law of thermodynamics, in terms of: "Heat always flows from objects at a higher temperature to objects at a lower temperature” (p. 333), which then remained in the classroom throughout the teaching sequence. Following a series of activities, including experiments with melting ice cubes, a pivotal event occurred when the children evacuated the classroom due to a winter fire drill, without their coats. Upon return, a dialogue commenced where the children related this experience of freezing to the taught subject. One of the children expressed that normally "the coat traps all your body heat" (p. 334), but now there was a heat transfer from the body to the cold air. In other words, the children came to adopt the heat-flow model and conceptualise 'heat' as an object or substance as a result of the teaching effort and the shared experience.

\section{Laboratory Exercises in Science Education}

Practical laboratory exercises have long been taken for granted as an integral part of science education. Laboratory teaching has been grounded theoretically, for instance, in Dewey's (1938/1997) call for authentic experiences, Piaget's (1929) emphasis on our sensorimotor experiences in constructing abstract concepts, and his use of simple physical experiments to probe children's understanding of natural phenomena, scientific and mathematical concepts (e.g. Piaget 1930). It also relates well with Vygotsky's (1962) emphasis on appropriation of a range of artefacts as an important aspect of learning.

However, reviews of laboratory practice in science education have revealed that laboratory exercises in school are often carried out without a clear purpose or learning objective, and against a background of limited empirical evidence of effects on students' learning (Hofstein 
and Lunetta 1982, 2004; Tobin 1990). In particular, Hofstein and Lunetta (2004) argue that although school laboratory activities have the potential to support science learning, this is inhibited when students are expected to follow "cookbook" instructions that provide limited opportunities for minds-on reflection. In conclusion, they request:

...teaching strategies, assessment tools, and resources that are effective in helping teachers and students to attain important learning goals that

- engage students with different abilities, learning styles, motivational patterns, and cultural contexts;

- engage students in using inquiry empowering tools and strategies; and

- engage students in justifying assertions on the basis of scientific evidence (Hofstein and Lunetta 2004, p. 48).

In the discussion section, we will revisit how our study may contribute to the development of science education practices that are closer aligned with the call put forward by Hofstein and Lunetta (2004).

\section{Infrared Imaging in Science Education}

Infrared (IR) imaging or thermography - the technology in focus of the current study - is a visualization technology with particularly promising educational laboratory prospects in thermal science (Vollmer et al. 2001; Vollmer and Möllmann 2010; Möllmann and Vollmer 2007; Xie and Hazzard 2011; Xie 2011; Short 2010). The contrast to traditional thermometer measurements is captured enthusiastically by Xie (2014):

With an IR camera, you get thousands of temperature data points at once and these data points are instantly used to create an easy-to-understand picture on the camera's screen. All you need to do is to point the camera towards the subject, just like what you do with a conventional digital camera. With a holistic image that shows the dynamic change of a temperature field, you will be able to see subtle, transient phenomena that would otherwise go unnoticed.

Infrared imaging depends on the phenomenon that all bodies above a temperature of $0 \mathrm{~K}$ emit radiation, the spectrum of which lies predominantly in the infrared range for objects at temperatures below $1000 \mathrm{~K}$. An IR camera detects the IR radiation spectrum from the different parts of the surface of solid objects or liquids. In turn, the temperature is calculated from Planck's law of blackbody radiation, modified by assumptions of the emissivity $\varepsilon$ of the particular surface. The temperature of the different parts of the surface is then rendered visually as an image on a screen, where the temperature range is represented by various colour coding alternatives (Vollmer and Möllmann 2010). Robust and easy-to-use hand-held IR cameras, such as FLIR i3 and FLIR E4, have been developed for professional applications, such as detection of heat leakages from buildings. In addition, with the introduction of IR camera accessories for smartphones, such as FLIR ONE or Seek Thermal, the technology is becoming an increasingly viable option for application in science and technology education.

Vollmer, Möllmann, and colleagues (Vollmer et al. 2001; Möllmann and Vollmer 2007; Vollmer and Möllmann 2010) bring forth the potential of IR imaging in science and engineering education, in subjects such as thermodynamics and mechanics. Similarly, Xie (2011; Xie and Hazzard 2011) has grasped the opportunity presented by IR cameras to inspire inquiry-based approaches in physics and chemistry education, and has created a series of IR experiments for educational application (Xie 2014). Pendrill, Karlsteen and Röjdegård (2012) have shown how IR camera measurements may provide useful input to model the cooling of a braking roller-coaster train. Overall, IR imaging holds the promise of making Erickson's (1985) vision come true, since students are now able to see heat, not only in their mind's eye, but moving on a screen. 
In terms of application of students' interaction with IR imaging in practice, Cabello, NavarroEsbrí, Llipis and Torella (2006) have described the use of IR cameras in a laboratory component of a thermal engineering course to help students connect theory and real thermal phenomena. In addition, Naghedolfeizi, Arora and Glover (2011) achieved good learning outcomes regarding the nature of laboratory work and measurements when undergraduate students measured heat exchange using IR-camera imaging and computer simulations. Furthermore, Atkins, Velez, Goudy and Dunbar (2009) have developed a science museum exhibit involving IR cameras. They found detailed task instructions to be inhibiting for the visitors, who tended to find imaginative ways to use the cameras without such instructions, due to their rich experience of different types of thermal phenomena from everyday life. Examples included taking thermal measurements as they rubbed their hands together or bringing in melting snow from outdoors.

In secondary education, Cazzaniga, Gilberti and Ludwig (2011) introduced IR cameras for detecting building insulation problems to a group of building surveyor students. A teaching sequence was developed with the aim to connect physics concepts to practical application of vanguard technology, as well as to current environmental challenges. As an outcome, the students were found to search for a wide range of explanations for heat dissipation, and provided highly favourable evaluations of the activities overall. Kröger (2012) presents a series of experiments, designed to support a learning progression in relation to energy throughout grades 7-10, focusing on four characteristics of energy (Duit 1984): energy conversion or transformation between different forms; energy transfer; energy degradation, and; energy conservation. Several of the suggested experiments involve IR cameras, including measuring the increased temperature due to friction as a block slides down a plane, and the increase in temperature as a metal ball strikes the ground after a 1.5 meter drop. Similarly, Dexter (2013) has developed a series of IR camera experiments designed to expose the three mechanisms of heat: conduction, convection and radiation. Twelve pupils in grade 6 and 7 were invited to carry out the experiments, in which they analysed the generated IR imagery and time series graphs of the temperature of the studied objects. In her evaluation of the technology for educational purposes, Dexter highlights the opportunity to see heat in real time and the user-friendliness of the equipment as advantages of applying the technology, although the high cost of the equipment was viewed as the main drawback for schools.

As part of our own research, we have conducted a small-scale qualitative study (Schönborn et al. 2014) where eight $7^{\text {th }}$ graders carried out experiments involving a sheet-metal knife and a piece of wood, respectively, in a predict-observe-explain (POE) fashion (White and Gunstone 1992). The pupils were first asked to touch and predict the temperature of the objects, and then asked to hold the objects with their thumbs for two minutes, and measure the temperature with IR cameras or digital thermometer themselves, or analyse prepared still IR images. As a result, the pupils experienced an emotionally charged cognitive conflict (Posner et al. 1982), as the metal felt colder than the wood in spite of their measurements showing the same room temperature. The pupils did not manage to resolve this conflict throughout their engagement with the experiments, however, which was attributed to the lack of a model of heat flow to anchor their perceptions.

\section{The Social and Affective Dimensions of Science Learning}

Vygotsky (1978) is central to studying how the social environment influences learning. With the notion of a zone of proximal development, he referred to the difference between what an individual is capable of doing, on the one hand, by him- or herself, and, on the other, when stimulated by the social environment or assisted by a more knowledgeable person, such as a parent or teacher. Similarly, Wood et al. (1976) introduced the idea of scaffolding as what a 
mother does upon encouraging and guiding a child in problem solving, a notion that later has been applied to learning contexts in general. Even though Piaget has become strongly associated with a focus on the individual's conceptual learning, he also acknowledged the crucial role of the social environment and cooperation in a child's moral and intellectual development (e.g. Piaget 1932). The research by Howe and colleagues (e.g. Howe 1998) described above is one example of the interest in the role of peer-to-peer collaboration in science learning.

Apart from the cognitive and social dimensions of learning, the affective dimension, involving issues of interest in, and motivation and attitudes towards science education (Osborne et al. 2003; Sjøberg and Schreiner 2005), is central to developing practices that are more effective and appealing to our students than at present. One way to operationalise how affective factors are involved in students' interaction with each other and tasks at hand is to look for indications of their personal or collective ownership of their learning (Enghag and Niedderer 2008). Example indications of ownership in a small-group setting would include if a group of students chooses to work with a particular task in an area of study, and is in control of how to perform and report the work, or when an individual student returns to a certain issue throughout the work, and is not satisfied until he or she has settled on an answer.

\section{IR Cameras Invite Instant Inquiry}

Discovery and inquiry learning approaches have the aim of increasing motivation and learning in science education, and have been influential in curricular development (Klahr et al. 2011) in the USA (Olson and Loucks-Horsely 2000) and Europe (Rocard et al. 2007). However, it has also been recognised that for effective discovery or inquiry learning, learners need guidance and scaffolding in the form of carefully designed learning environments and continuous assessment of the progress of their learning, combined with intervention by teachers and more experienced peers when required. ${ }^{1}$ When left to their own devices, students have a slim chance of inquiring into or discovering phenomena or patterns that are found worthwhile by their teachers.

With the intuitive character of IR camera technology, a type of real-time visual augmentation device - essentially a thermal looking glass - pupils can immediately act upon 'what-if' questions driven by their genuine curiosity, such as "how warm is the sun?", and observe what it looks like on the camera screen (Xie and Hazzard 2011). We characterise this type of activity as a case of instant inquiry, a term that was suggested by Brunsell and Horejsi (2010) for the immediate analysis science students may engage with in relation to digital camera images, but applied here to dynamic IR imaging. In this setting, the inherent thermal focus of the technology constrains the types of questions pupils come up with, so that they do not lose focus on the overarching task of learning about thermal phenomena. In other words, the IR camera provides productive disciplinary affordances, in terms of "the inherent potential of [a] representation to provide access to disciplinary knowledge" (Fredlund et al. 2012, p. 658) in the thermal domain.

\footnotetext{
${ }^{1}$ For example, see the debate on the merits and shortcomings of inquiry and discovery learning in the journal Educational Psychologist (Hmelo-Silver et al. 2007; Kirschner et al. 2006).
} 


\section{Materials and Methods}

\section{Context of the Investigation}

The present study is part of a longitudinal investigation (e.g. Helldén 2005; Tytler and Peterson 2005), in which two of the authors (JH and FJ) have been involved in the teaching and learning of thermal phenomena among a class of primary school pupils. In a previous study, conducted when the pupils were in first grade (Haglund et al. 2012, 2014), we investigated the degree to which pupils were able to come up with their own analogies for two physical scenarios: a frying pan being heated by a hot-plate, and the mixing of marbles, respectively. In the present study, conducted when the pupils had started the fourth grade, at ages 9-11 years old, the focus was on teaching and probing their understanding of central concepts in thermal science, such as thermal equilibrium, heat and temperature. In addition to the class followed in grade 1 , we now also worked with their parallel class, in total $N=46$ pupils.

Along another dimension, the current study also fits within an overall research program of investigating how hand-held IR cameras could be used in the teaching of thermal science at different educational levels, including secondary school (grade 7) (Schönborn et al. 2014), upper secondary school, and in thermodynamics at the university level.

Furthermore, the present research may be characterised as a design study, which involves intervention in a real-life classroom setting, in the form of iterative development, testing and assessment of teaching sequences that target 'domain-specific learning processes' (Cobb et al. 2003). Therefore, in relation to the previous study on a group of $7^{\text {th }}$ graders (Schönborn et al. 2014), the current study is a second iteration of how to make use of IR cameras in compulsory physics education. In particular, the choice of introducing a heat-flow model to the pupils was informed by challenges previously experienced by the $7^{\text {th }}$ graders in accounting for why metal feels colder than wood at room temperature.

In practice, the teaching of thermal science by use of IR cameras was carried out as part of The Sweden Trip, a storyline (Creswell 1997) that ran for seven weeks, covering many school subjects, including physics and English as a second language. Within the storyline, the pupils were divided into "families" and were presented with the scenario that they were about to move from Australia to Sweden. The pupils were told that Sweden has a cold climate, and thus would have to learn about how to stay warm in the north, through appropriate clothing and insulation of buildings, and about different energy sources and means to generate electricity. The thermal science teaching corresponded to the following core content in the Swedish grade 4-6 physics curriculum (Skolverket 2011), with the IR-camera activities focusing particularly on the second statement:

- Indestructibility of energy and flows, different types of energy sources and their impact on the environment, as well as the use of energy in society.

- Energy flows between objects with different temperatures. How the flow of energy can be affected by such means as clothes, thermos and house insulation.

In Probing understanding, White and Gunstone (1992) call for more imaginative ways to assess students' ideas, beyond traditional written methods. One of the techniques they propose is 'predict-observe-explain' (POE). POE can be adapted for various settings, but typically involves a teacher exposing students in class to a series of 'specific events', such as practical demonstrations or experiments. The students are first asked to predict what will happen in the event, write down their predictions individually, and share them with each other. If there are different predictions, these can be compared and discussed. Next, the students observe and report what actually happens while the experiment is performed. 
Finally, they are encouraged to explain what happened and reconcile any inconsistences, in comparison with their predictions. According to White and Gunstone, an essential objective of POE is to create scenarios where pupils feel comfortable in generating predictions and where this process is drawn from their own unique reasoning. For the prediction phase there are several possible formats for generating pupils' responses, ranging from making a choice from a prediction list to a more open ended approach, for example where pupils are asked to write down their predictions freely.

All whole-class demonstrations and small-group laboratory exercises in the present study were structured in accordance with the POE approach. In the small-group exercises, we encouraged each participant to make a prediction and share it with the rest of the group prior to making the experiments. We adopted the open ended approach for generating predictions and provided a template for the pupils to write them down. At times, considering the age of the pupils, we did not require them to provide written predictions, but the crucial issue was for everyone to have the opportunity to communicate their view of what would happen. In the whole-class setting, we asked the pupils systematically to make predictions orally, and those who raised their hands shared their expectations of what would happen with the others.

Apart from the methodological research rationale, the POE approach adheres well with the overall aim of the Swedish compulsory school physics curriculum, in particular in relation to systematic studies:

Through teaching, pupils should be given the opportunity to put questions about physical phenomena and contexts based on their own experiences and current events. In addition, teaching should give pupils the opportunities to look for answers to questions by using systematic studies and different types of sources (Skolverket 2011).

The IR camera activities were held on four occasions spanning a three-week period. On the first occasion, the pupils were introduced to hand-held IR cameras (models FLIR i3 and FLIR E4), and asked to select and measure the temperature of three objects in the schoolyard, while divided as per their "Sweden Trip" families. This exercise was conducted in a POE fashion, where the pupils predicted and noted on a worksheet what they thought the temperature of the objects were, observed the objects with the IR camera, and then explained any inconsistencies. In addition to becoming acquainted with the equipment, one objective was to introduce the idea of thermal equilibrium, by highlighting the fact that objects in the same environment tend to the same temperature.

On the second occasion, the pupils were introduced in a full-class setting to a simple macroscopic heat-flow model (e.g. Rosebery et al. 2010; Linn and Eylon 2011; Arnold and Millar 1996), according to which heat or energy flows spontaneously from an object of higher temperature to an object of lower temperature, with which it is in thermal contact. The model was demonstrated with an animation, and by projecting the screen of a real-time IR camera display while heat flowed from a metal object at room temperature to a metal object that had just been taken out of the freezer. This demonstration also followed the POE approach, for instance in that the pupils were asked to predict what would happen in the animation when the warm and cold objects were put together.

On the third occasion, the pupils were once again divided into their families for small-group laboratory exercises with the IR cameras, rotating between three different stations. The three stations involved the following exercises:

1. Touching and measuring the temperature of a piece of wood and a sheet-metal utility knife with an IR camera, and measuring the objects while holding them for a two minute period (Schönborn et al. 2014). The objective was for the pupils to perceive the difference in heat flow through a thermal conductor and an insulator, respectively, 
and to target the alternative conception of our sense of touch as an accurate thermometer.

2. Submerging each of their two hands into a bucket of cold and warm water, respectively, and then submerging both hands into a bucket of lukewarm water simultaneously. As proposed by Mach (1896/1986), this exercise involved the phenomenon that with our sense of touch, we may experience the same temperature in quite different ways, depending on the initial temperature of our hands.

3. Pouring warm water into a coffee mug and a plastic cup and measure what happens to the temperature of the objects with an IR camera. Measuring the temperature on the surface of your body, while wearing a t-shirt and a jacket, respectively. Both these exercises dealt with the phenomena of heat conduction and thermal insulation.

Finally, on the fourth occasion, the pupils were given a full-class demonstration of using an IR camera to measure the thermal changes associated with placing a piece of metal over a candle flame, and placing the end of the sheet-metal knife into warm water. The teaching sequence ended with a creativity exercise, in which the pupils were asked to come up with and draw objects that they would like to measure with an IR camera in their family groups.

The pupil dialogue in focus in the present study is taken from one of the families made up of two girls and three boys, as they engaged with the third station task above, pouring warm water into a coffee mug and a plastic cup.

\section{Data Collection}

The small-group laboratory exercises, full-class presentations and demonstrations were video and audio recorded with hand-held or tripod-mounted video cameras. In addition, pre- and post-tests of the pupils' understanding of the energy concept were administered, screenshot IR images were taken of some of the experimental activities, and the drawings made during the creativity exercise were gathered. We strictly adhered to the ethical requirements stipulated by the Swedish authorities for conducting educational research in schools. Informed consent to participate in the study was gathered from the pupils' parents and pseudonyms of the participants are used throughout the text.

\section{Data Analysis}

\section{Selection of Data}

This study focuses on a 9:35 (minutes:seconds) video clip obtained from the third occasion of activities where one of the pupil families interacts as a small group while performing the third laboratory station during the third occasion of data collection (pouring warm water into a coffee mug and a plastic cup, see Fig. 1). The methodological approach of purposefully selecting a single video sequence for analysis adheres to the following guidance on video analysis in educational research:

\footnotetext{
In selecting video chunks to tell a story or a piece of a story or to show what an instance of a given event phenomenon looks and sounds like, the researcher may look across a vast array of video records to find the most representative instance or instances - perhaps the most salient video chunks that best illustrate and represent one day or month of data collection (Derry et al. 2010, p. 12).
}

The particular video sequence was selected based on its richness and complexity. It presents many important aspects of pupil interaction with the equipment, with each other, and one of the researchers $(\mathrm{JH})$, where the pupils express a wide range of underlying conceptions in relation to the observed and experienced thermal phenomena. The video clip thereby does not serve as a typical example, but rather demonstrates highly engaged pupils at the peak of their abilities, an exemplary situation that we were very excited about as observers in the study 
context. In addition, two of the pupils in the group had been in previous focus during the study conducted while they were in first grade (Haglund et al. 2012, 2014), which also serves to emphasise the continuity of the longitudinal approach of the research programme.

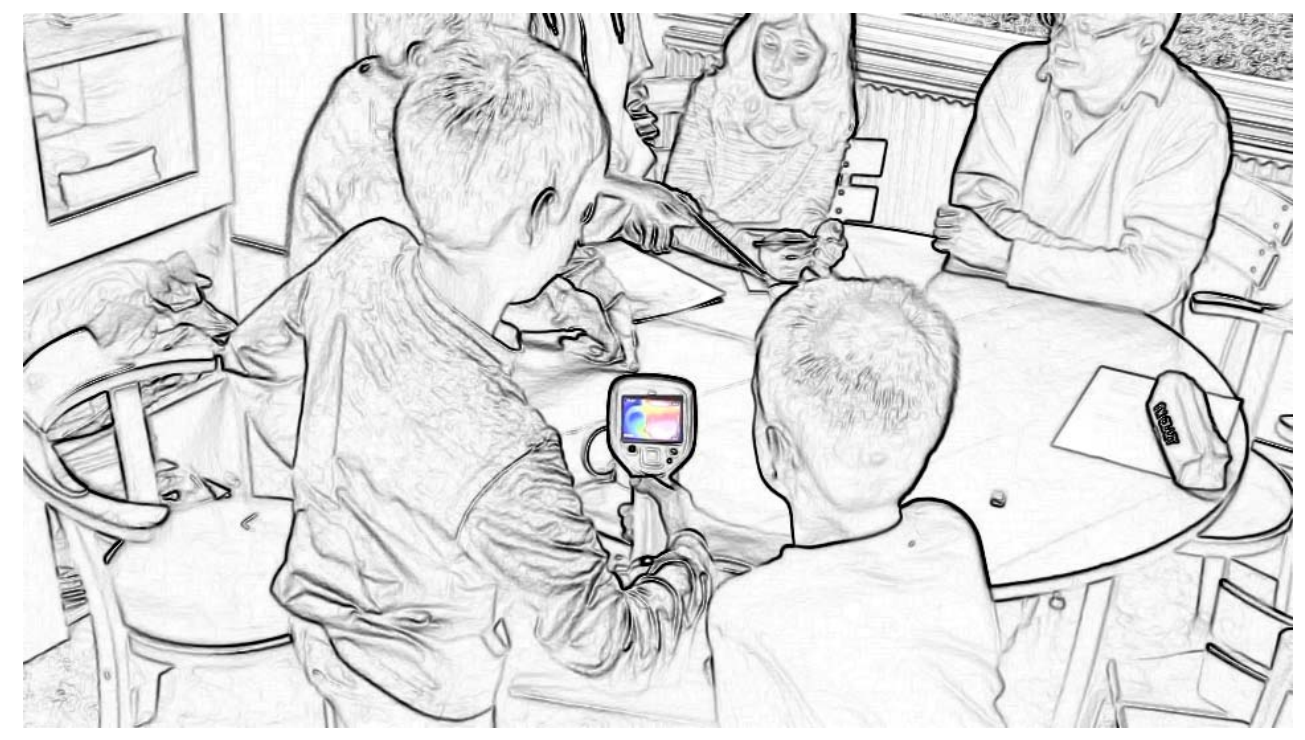

Fig. 1 Schematic generated from a video screenshot obtained during the small-group IR camera exercise showing pupils investigating the temperature change of a plastic cup and a coffee mug, as hot water is poured into them

\section{Narrative Description of the Data}

The selected video sequence was transcribed verbatim in Swedish. For the purpose of presenting the results, relevant excerpts were translated into English. These constitute the core of a narrative description, which is described as four chronological episodes. The ambition of our analysis is to provide a thick description (Geertz 1973) of the observed group interaction, in the sense of not only communicating what happens, but also interpreting the meaning of the discourse in the studied context. We therefore aspire "to draw large conclusions from small, but very densely textured facts" (p. 28), through the study of an exemplar of pupil interaction. In a similar vein, within a science education research context, diSessa (2014) argues in favour of microgenetic learning analysis of student interaction as a way to achieve a fine-grained near exhaustive analysis of learning in particular contexts in a moment-by moment way. In application of diSessa's terminology here, fine-grained refers both to time-scale and the very fine distinctions in meaning-related conceptual understanding. In the present study, episodes were selected that were found to be particularly rich in meaning, and constituting exemplars of sustained observation, instant inquiry, and conceptual understanding of thermal phenomena. In line with the intentions behind developing a thick description of the interaction and providing a microgenetic analysis, deeper meanings of the exchanges within these episodes and the participants' underlying conceptual understanding were further sought and interpreted.

\section{Results}

In the Results section, the group's interaction with the laboratory exercise is presented in a narrative fashion as four chronologically ordered episodes, in the form of corresponding transcript excerpts and analyses. The description of the interactions of each episode is followed by an analysis of the conceptions of heat that the children express, and the conceptual challenges that they encounter. 


\section{Episode 1 - Making predictions}

This episode consists of a suite of predictions, and the pupils' and the researcher's discussions thereof, that framed the pupils' interpretation of the observed scenarios that follow in subsequent episodes. Specifically, the group in focus enters the room where the experiment with the plastic cup and the coffee mug has been prepared. Two of the boys, Stefan and Jonas, immediately pick up the IR camera and start exploring freely, such as measuring the temperature of the objects after the previous group has left. Researcher $\mathrm{JH}$, who guides the exercise, calls the pupils' attention at the beginning of the exercise:

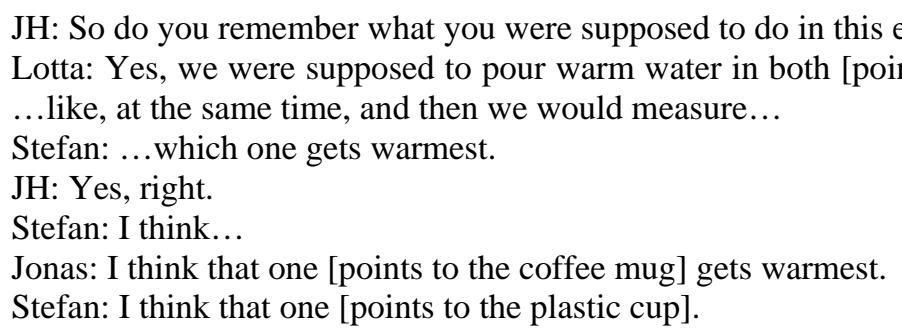

At the beginning of the episode, Lotta recalls the purpose of the task, and Stefan assists her interpretation of what is required. This is immediately followed by Stefan and Jonas spontaneously generating their predictions of the specific event. Intriguingly, already at this early stage, their predictions are in conflict with one another. As an advantageous aspect of the collaborative POE approach, these predictions set the stage for the pupils to argue for and justify their relative positions and for taking an interest in what will actually happen during the physical experiment. It also shows that the pupils are not afraid to express their own personal views.

$\mathrm{JH}$ goes on to point out the communicated difference in views of what the pupils predict will happen:

JH: But you thought diff... You had different hypotheses ${ }^{2}$ here. What do you think will happen in this cup [holds the plastic cup] and what do you think...? [points to the coffee mug]

Jonas: Well, these [points to the coffee mug] are made to hold the heat.

Lotta: This one [lifts the plastic cup] will get colder.

$\mathrm{JH}$ : This one [holds the plastic cup] will get colder.

Kalle: [touches the coffee mug, responds to Jonas in a snappy tone:] No, they are not.

Jonas: Yes, they are. That's why it's still warm.

Stina: It's boiling hot water, right?

JH: It will be... well, we have that kettle out there... so we have...

Jonas: About 75 degrees. I already checked that.

In line with the overall POE approach, JH provides scaffolding to encourage all pupils in the group to make predictions and expose any different opinions. Jonas supports his earlier prediction that the coffee mug will get warmest by referring to its function of holding the heat. Kalle picks up on the function of the mug, but disagrees overtly with Jonas. Although we do not know how Kalle construes the function of a coffee mug (it might be that it prevents burning of one's fingers), at least it indicates emotional engagement with the task and others' justifications of their predictions. In response, Jonas backs up his statement with the fact that the coffee mug is still warm from the previous group's experiment. Lotta's prediction is consistent with Jonas's in that the plastic cup will get colder (supposedly colder than the coffee mug, but not colder than at the initial state). Subsequently, this becomes the consensus

\footnotetext{
${ }^{2}$ In the communication with the children, we used expressions such as 'hypothesis', 'prediction' and 'what you think will happen' interchangeably in relation to the expected outcome of a particular experimental situation.
} 
view of the group (apart from Stefan - as exemplified in the first excerpt above - who adheres to his original assertion). Next, Stina inquires into the conditions of the task, how warm the water is. In a proactive fashion, Jonas has already measured the temperature of the water, probably using the IR camera, and swiftly answers her question.

\section{Conceptions of Heat Expressed in Episode 1}

At this early stage, we can only be tentative in analysing what underlying conceptions reflect the pupils' predictions. Overall, however, it is perhaps worrisome that four of the five pupils settle on a prediction that the coffee mug will get warmer than the plastic cup, which in the following will turn out not to be the case (at least not immediately). The task at hand clearly confronts the pupils with a conceptual challenge at this stage.

Why is it that the children make this prediction? Jonas justifies his prediction with the function of a coffee mug, i.e. to hold the heat. In line with Erickson (1985), this comes across as an ad hoc explanation, or a vague association to coffee mugs as good at dealing with heat. He further backs it up by the fact that the coffee mug is still warmer than the plastic cup from the previous experiment. It is therefore not unreasonable to think that it will remain warmer in the experiment.

Furthermore, it is interesting that Jonas speaks of heat as a noun, which Erickson (1985) and we (Schönborn et al. 2014) found to be rather unusual in children's explanations of thermal phenomena. Heat is conceived as something that is held in the coffee mug. However, the fact that he sees the coffee mug as a kind of insulator, but predicts that it will have a high temperature on the outside, seems to be part of the conceptual challenge.

\section{Episode 2 - Observing and Explaining the Experiment}

Once the pupils have made and justified their predictions, JH initiates the next phase of the POE investigation, i.e. performing the actual experiment and observing what happens (see Fig. 1):

JH: Okay. Who's going to pour?

Stina: Me! [goes for the kettle]

Lotta: Me! [Lotta follows Stina. Stefan and Kalle deal with the IR camera. Stina and Lotta return with the kettle]

JH: Come on, look in the camera now! [Stina starts pouring water into the plastic cup, Kalle measures with the IR camera]

Stefan: Check out the water flowing.

Jonas: [looks in the IR camera screen] It looks really cool!

$\mathrm{JH}$ : Pour in that one, too... [points to the coffee mug] at the same time, like that [Lotta pours water into the plastic cup] What happens? What does it look like in the IR camera? [JH walks round the table and looks at the IR camera display] Let's look here, everybody.

Stefan: Oh damn, the Swedish flag, take a picture! The Swedish flag!

$\mathrm{JH}$ : What has it turned to? [points to the IR camera] So how warm is it on the big [coffee] mug?

Stefan: It is warmer down there.

Kalle: [sweeps the IR camera from the bottom to the top of the coffee mug] Warm, a bit in between, and cold.

JH: [points to the screen of the IR camera] So, it's 65 degrees down there on the mug... and how warm is it in the little [plastic] cup? [Kalle points the IR camera to the cup] It's 80 degrees. So, which one is warmest?

Kalle: The little one.

Stefan: That's what I said! /.../ I told you that one [the plastic cup] would get warm!

The overall striking feature of the above exchange in relation to these initial observations is the degree of engagement that the pupils display. This is manifested in at least two different 
ways. First, Jonas and Stefan express their excitement at the IR images as water is poured into the mug and the cup (see Fig. 2).

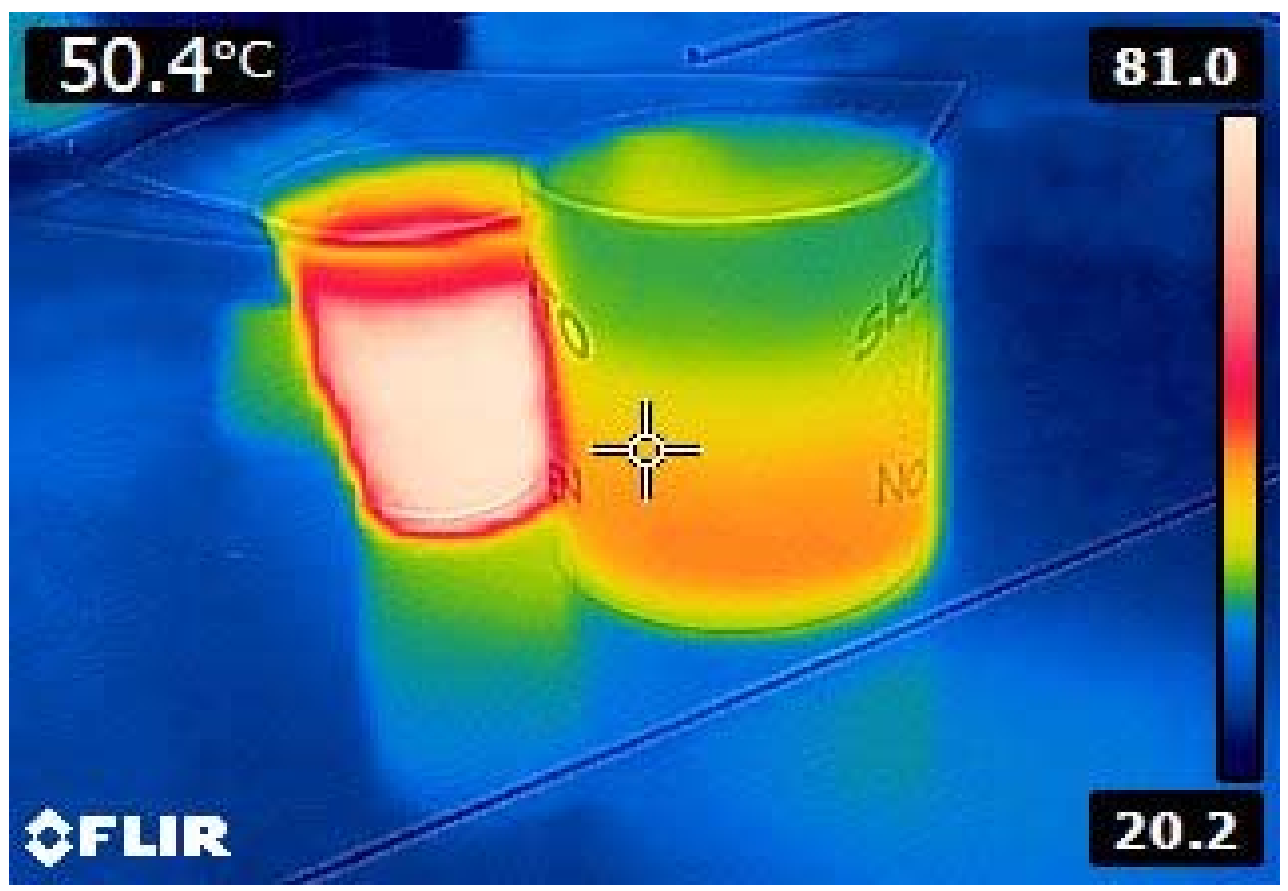

Fig. 2 IR image after warm water has been poured into the plastic cup to the left, and the coffee mug to the right. The cup is about $80{ }^{\circ} \mathrm{C}$, while the mug is $50.4{ }^{\circ} \mathrm{C}$ at the point of the crosshair cursor

In particular, Stefan notices the aesthetics in the similarity between the blue-yellow colour scale rendered on the IR display and the Swedish flag. Second, Stefan takes ownership of his own earlier prediction that the plastic cup would become the warmest.

Subsequently, JH turns the attention to the predictions of the other pupils:

$\mathrm{JH}$ : But you [turning to the other pupils] said that this one [the plastic cup] would get cold and that one [the coffee mug] would get warm.

Kalle: Yes, I said that this [points to the coffee mug] would get warm.

$\mathrm{JH}$ : So, now it turned out the other way around, from what you thought. How come this one [points to the plastic cup] is warmer on the outside?

Lotta: [points to the plastic cup] Because it is thinner.

$\mathrm{JH}$ : Because it's thinner.

Here, $\mathrm{JH}$ points out that the outcome of the experiment is different from what most of the pupils initially predicted, and Kalle agrees with this. When JH asks them to come up with explanations, Lotta adequately mentions the thickness of the walls of the cup as a relevant factor.

Suddenly, Jonas looks at the screen of the IR camera and notices some changes and continues to engage in the observation:

Jonas: [looks at the IR camera display] Hey, now this [points to the coffee mug] gets warmer. It's getting warmer now [looks at JH]. /.../

Stefan: Look, it's rising [points to the IR camera]

$\mathrm{JH}$ : [points to the IR camera] 'Cause it was 60 degrees earlier. And now it is 70 degrees. So this one [the coffee mug] is getting warmer, whereas that one [the plastic cup] was warm already from the beginning.

Stefan: Now it [the plastic cup] is only 77.

JH: Now it is 77. How come that one [points to the plastic cup] has got colder?

Kalle: This [coffee mug] holds the heat. That [plastic cup] gets warm.

$\mathrm{JH}$ : So, this mug holds the heat better, and that one [plastic cup] gets warm. 
Kalle: ...gets warm...

Jonas: ...much quicker.

Kalle: ... at the beginning.

Jonas notices that the temperature of the coffee mug has continued to increase after water was poured into it. Then, Stefan pays attention to the temperature of the plastic cup, which now is "only" $77^{\circ} \mathrm{C}$, in relation to the initial $80^{\circ} \mathrm{C}$. In explaining the observed phenomena, Kalle offers the idea that the coffee mug holds the heat, whereas the plastic cup became warm immediately as water was poured into it.

At this stage, we would like to point out two features of this excerpt. First, the children are impressively inquisitive about how the experiment will continue, even when $\mathrm{JH}$ has asked them to explain the initial temperature readings rather than focusing on taking more measures. The attraction of interacting with the IR camera invites them to a sustained observation, which otherwise may have been more difficult to attain with traditional thermometer-based measurements. Second, coming up with the explanation of the thermal processes is an altogether collaborative effort, but only between these three boys, and the two participating girls do not engage in this interaction.

Now, JH encourages the sustained focus on further observations:

$\mathrm{JH}$ : What happens on the outside... down there on that mug? [points to the coffee mug] 70 degrees now. Jonas: About... about 70 degrees.

$\mathrm{JH}$ : Yes. And what is this [points to the plastic cup] like now, the little one? [Kalle points the IR camera] Now it's 75 .

Kalle: Well, it's falling anyway.

$\mathrm{JH}$ : So the temperature is falling. How come the temperature is falling?

Jonas: It's not so thick. [points to the plastic cup]

JH: It's not so thick. So what happens then?

Jonas: This [points to the coffee mug] has, like, insulation, you could say.

While the temperature of the coffee mug has settled on $70{ }^{\circ} \mathrm{C}$, Kalle notices that the temperature of the plastic cup is "falling", exposing an idea of temperature along a vertical scale. As an overall impression, given their age, it is remarkable how the pupils manage to keep track of the temperature changes of the two objects in relation to each other (see Fig. 3). Then, Jonas revisits the thickness of the objects as an explanation for why the temperature of the plastic cup is falling, but not that of the coffee mug. By analogy, he likens the thicker wall of the coffee cup to "insulation", which is exactly the role it serves from a physics point of view. 


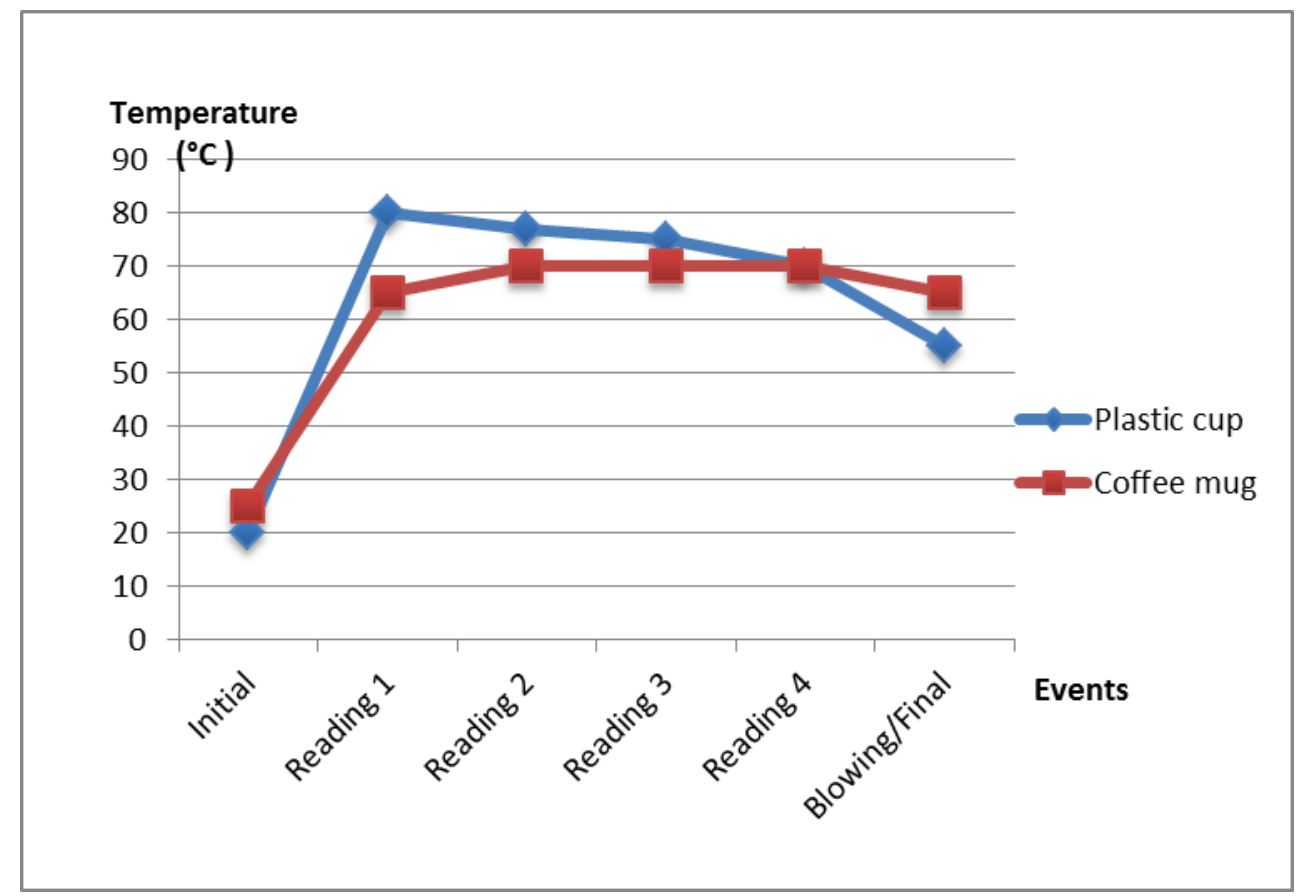

Fig. 3 Graph generated by the authors to visualize the temperatures of the plastic cup and coffee mug measured by the pupils while performing the task

In an effort to invoke further reasoning on causal explanations for the temperature observations, JH probes deeper:

$\mathrm{JH}$ : But... how come its [points to the plastic cup] temperature falls? What is happening?

Jonas: The heat comes out. [points outwards from the plastic cup]

JH: The heat goes out of it.

Jonas: Yes.

JH: I'd say that, too. What happens to this one [points to the coffee mug] then? Does heat go out of that one, as well?

Jonas: No. Only from above here... [moves hand from the water surface of the coffee cup upwards] it goes out. 'Cause if you feel, it steams. /.../

Kalle: [measures at the top of the coffee mug] You see. Now the heat rises a bit...

Jonas explains the falling temperature of the plastic cup in terms of an outward flow of heat to the surrounding air, further reinforced through gesture. This satisfies $\mathrm{JH}$, who turns to comparing the situation of the plastic cup with the coffee mug. In response, Jonas posits that heat only goes out of the coffee mug from the water surface on top. He justifies the heat coming from the surface with his sense of touch, and this is further confirmed by Kalle's IR camera measurements.

\section{Conceptions of Heat Expressed in Episode 2}

In comparison to the pupils' erroneous predictions prior to conducting the experiment, their lines of reasoning come across as much more adequate once they have the chance to observe and explain the phenomena.

First, Lotta highlights the thickness of the cups as a factor in order to explain that the plastic cup gets warmer than the coffee mug. Although not expressed in the chosen transcripts, when further probed, the group members also mention the different materials of the cups. The sustained focus maintained on relevant factors is impressive in relation to similar research on comparable age groups by Howe et al. (1995). Jonas interprets the coffee mug as an insulator, in order to explain why its temperature does not decrease as rapidly as that of the plastic cup. 
In explaining why the plastic cup initially gets warmer than the coffee mug, Kalle adopts Jonas's idea from the previous episode: the coffee mug holds the heat. In contrast, though, here the mug holding the heat goes along with it being colder on the outside than the plastic cup, which in turn is conceived of as turning warm immediately. Here, Kalle speaks of heat as a noun in relation to the coffee mug, but not the plastic cup, which supposedly immediately takes the temperature of the water, possibly by means of a process reminiscent of contagious action (Piaget and Garcia 1977).

In the last transcript excerpt, the children make more use of heat as a noun, but now also in relation to the plastic cup, when explaining why its temperature starts to decrease after some time: The heat comes out of the plastic cup. In contrast, when probed by the researcher, they do not think that any heat goes out of the coffee mug. Heat only leaves the water in the coffee mug from the water surface in contact with the air. This reveals a conceptual challenge in seeing conduction as a continuum of conducting heat more or less effectively (Tiberghien 1985). The coffee cup is thought of as an ideal insulator.

Stefan talks about the temperature of the coffee mug "rising" and later Kalle refers to the temperature as "falling” in the plastic cup. This reflects a conception of temperature as a level on a scale, adhering to language conventions. In contrast to Shayer and Wylam's (1981) study of children in comparable age groups, there is no indication that the pupils in the present study confuse heat and temperature. For instance, when Kalle says that "the heat rises", he seems to refer to an actual vertical movement of heat from the water in the plastic cup to the air above it, rather than confusing it with a temperature increase.

Overall, in the development of the experiment thus far, the pupils have collectively exposed an understanding of the earlier presented heat-flow model, where heat is seen as something that can move from warm objects to cold objects or be held within them by means of insulation.

\section{Episode 3 - Blowing on the Water Surface}

After the group has settled on their explanations for the observed phenomena, emanating from their original predictions, Stefan unexpectedly starts to blow on the water surface of the plastic cup. This is received with scepticism from Jonas:

Jonas: Why do you do that? You're just cooling it down.

Stefan: I'm going to check how warm it gets. [picks up the IR camera and directs it to the plastic cup]

Jonas: You will just drop it [the IR camera]! /.../ Now it's 70. /.../

$\mathrm{JH}$ : What happens when you're blowing then?

Kalle: He's just making ripples. [Looks at the IR camera display, while Stefan continues to blow on the water surface] Now it's getting a bit colder.

Stina: Hey, Kalle!

$\mathrm{JH}$ : Measure up there on the surface... [points to the water surface] ...what happens there.

Stina: But, Kalle. Kalle! [Stina does not attract the others’ attention, and gets frustrated] Oh!

JH: Now, it's 55 degrees. When he's blowing, it's getting colder.

Stina: Hey, Kalle!

JH: Have you experienced that before... when you blow on a surface of warm liquid, like this...?

Jonas: Yes.

$\mathrm{JH}$ : What happens then?

Jonas: When you blow on, for example soup, it gets colder. /.../

The above excerpt is a prominent example of an instant inquiry event in this study. Stefan suddenly ponders what will happen to the temperature if he blows on the water surface, and with access to the IR camera he can immediately act upon this curiosity. Jonas, in turn, frames this initiative as simply ruining the experiment, as he spontaneously predicts that it will cool the water down. However, in contrast to Jonas, JH encourages Stefan to continue 
the exploration, and Kalle uses the IR camera to indeed confirm that the temperature of the water surface decreases. Even though the act of blowing on the water surface was not explicitly stated to be performed in the task instructions, Stefan and JH found it a relevant action for learning more about thermal phenomena. In this situation, Stefan clearly produces a "what if" scenario, is able to test it and gets an unequivocal answer in a matter of seconds: instant inquiry. With a digital thermometer, in comparison, it would be difficult to measure the temperature precisely at the water surface. Following the event, JH appeals to the pupils' experience of similar situations, and Jonas recognises a parallel with warm soup, in that it will get colder when you blow on it, so that you do not burn yourself.

\section{Conceptions of Heat Expressed in Episode 3}

In his argumentation for why Stefan would ruin the experiment by blowing on the water surface, Jonas says that it will cool the water down. This reveals a basic intuition for heat convection in the contact between the water and the air flow, grounded in the everyday experience of blowing on soup.

\section{Episode 4 - Placing a Pencil in Warm Water}

In the episode above, while Stefan was blowing on the water surface, Stina unsuccessfully attempted to call for the group's attention. When the rest of the group eventually turns the focus toward her, she proposes an idea that evolves into yet another compelling case of instant inquiry:

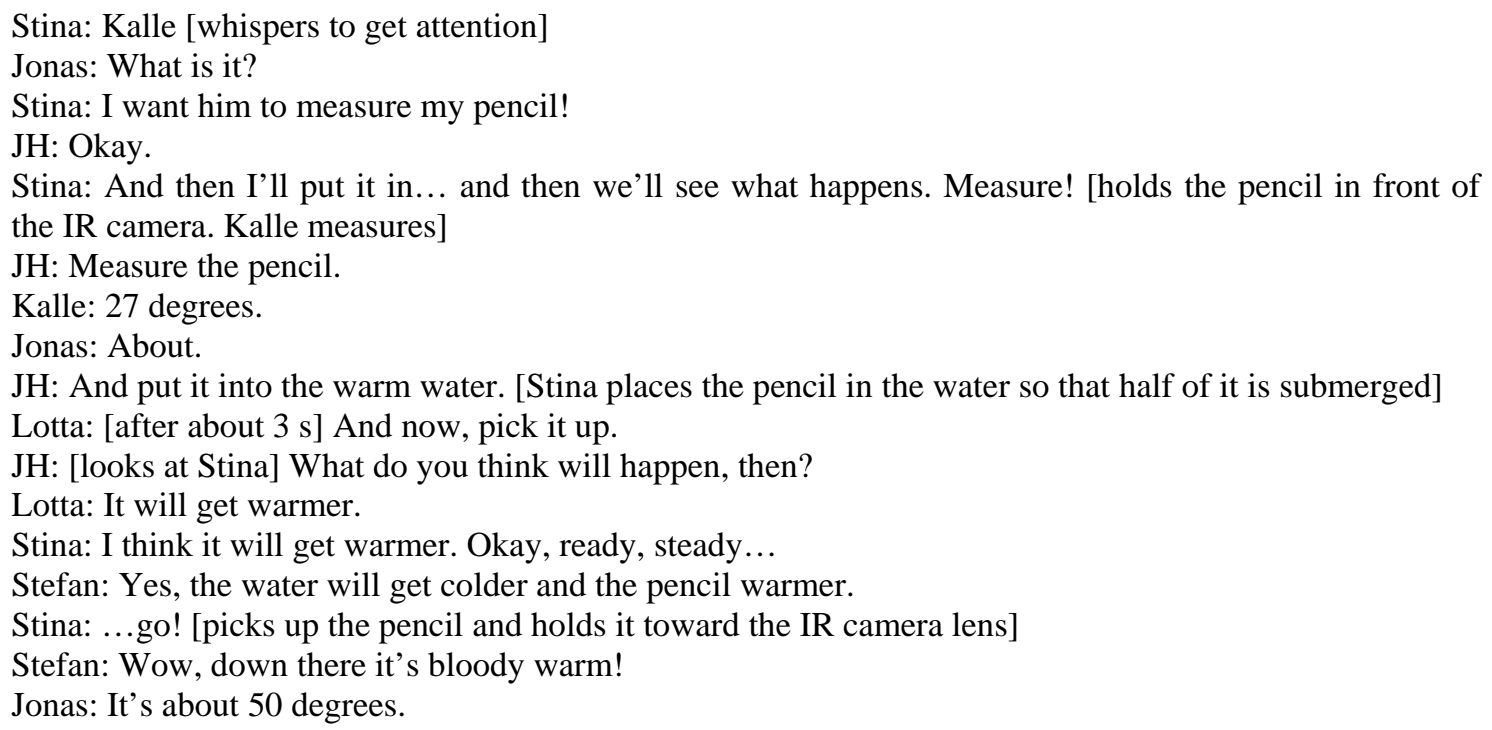

The excerpt demonstrates how Stina wonders what will happen when she places a pencil in the warm water. As was the case with Stefan previously, she is able to reach an answer of the temperature of the pencil before and after placing it in the water through interaction with the IR camera. JH sees this as an opportunity to perform another POE experiment within the overall POE, and asks the pupils to come up with their own predictions based on Stina's unfolding initiative. Lotta predicts that the pencil will get warmer, but Stefan takes this idea one step further. Not only does he predict that the pencil will get warmer, but also that the surrounding water will get colder. JH probes him for further explanation:

JH: But, as you said, Stefan... what happened to the water temperature when you put in the pencil? 
Stefan: It got colder. /.../ Because the cold ${ }^{3}$ in this one... [points to the pencil] takes cold in this one... it cools down a bit [points to the water] ....and then it gets warm on here [points to the pencil]

Lotta: I mean, this one [holds the pencil] takes the heat. This [the pencil] like, takes the heat.

JH: The pencil takes the heat.

Lotta: And heat goes up.

Jonas: It [the pencil] sucks in the heat.

$\mathrm{JH}$ : So heat goes away from the water... and goes into the pencil...?

Lotta: Yes. /.../

Stina: Check how warm this is. [holds the pencil in front of the IR camera for Kalle to measure]

Jonas: But it's not getting warmer than it was in the cup.

Stina: Okay, 55 then.

Stefan explains the situation in terms of a transfer of cold from the pencil to the water, which is not unreasonable at this macroscopic level, even though he struggles to verbalise this idea. However, Lotta rather sees the situation as a matter of the pencil taking up heat. This idea is further reformulated as heat going up into the pencil, or - as Jonas expresses - the pencil "sucks in the heat". In the final turns, Stina wants to know how warm the pencil is after it has been removed from the water, but Jonas argues convincingly that it cannot have got warmer than the water. Without checking, Stina concludes that it will have to be $55^{\circ} \mathrm{C}$.

Afterwards, just prior to the end of the session, Kalle and Jonas take a final reading of the temperature of the coffee mug and notice that by then it has "got much colder" and is now "sixty something".

\section{Conceptions of Heat Expressed in Episode 4}

Stefan's prediction that the pencil will get warmer and the water immediately surrounding it will get colder is impressive and compelling for at least two reasons. First, it is a fruitful application of the previously communicated heat-flow model, with a focus on both objects involved in the heat exchange. This is a clear expression of transmission (in this case of cold), rather than a matter of contagious action where one object adopts the temperature of another (Piaget and Garcia 1977). Second, even though they are able to measure the temperature increase on the surface of the pencil, there is no way for them to confirm the temperature decrease of the locally surrounding water; this is a purely theoretical inference and a result of applying the adopted model.

Lotta and Jonas subsequently speak of heat as a noun, a kind of substance-like entity that the pencil "takes" or "sucks" in from the water, which Shayer and Wylam (1981) did not find among children in the same age group, but only among older children. As in the case of Kalle's assertion in Episode 2 that "the heat rises", we interpret Lotta's explanation here that the "heat goes up" as consistent with the idea of a movement of heat upwards along the length of the pencil - although less adequate here due to the fact that wood is an insulating material, rather than an indication of a conflation of heat and temperature. Even though these expressions reflect the idea of heat transmission to and through the solid wood of the pencil, they also come across as rather odd to an adult's ears, as early attempts of adopting the heatflow model.

Jonas's inference that the pencil cannot have got warmer than the surrounding water may hint at an emerging understanding of thermal equilibrium, but is also consistent with a contagious action view on heat.

\footnotetext{
${ }^{3}$ In Swedish, Stefan says "det kalla”, which literally translates into 'the cool' by use of an adjective as noun. This expression does not have an obvious English equivalent, but is close in meaning to 'the cool stuff' or 'the cold'.
} 


\section{Discussion}

In the Discussion, we reflect upon the outcome of the analysed laboratory exercise by revisiting the research questions, and raise potential implications for science education research and practice.

\section{Revisiting the Research Questions}

- How can IR cameras inspire sustained observation and instant inquiry in a fourthgrade small-group laboratory exercise on heat?

In the studied POE laboratory exercise, the pupils maintained focus on the overall learning objective of trying to understand the observed thermal phenomena. This was manifested by sustained observations with the IR camera of the temperatures of the two objects throughout the exercise, interspersed by episodes of instant inquiry emerging out of the curiosity and initiative of individual pupils. What are the factors behind the sustained focus in this particular session? We frame a response in terms of the three dimensions that Lunetta and Hofstein (2004) identify as particularly important for advancing the school laboratory practice: targeting a diversity of students; inquiry empowerment; and encouragement of students to provide evidence-based justifications.

As for catering to learning among students with a variety of needs and preferences, we would like to identify Stefan as of particular interest. Stefan is an active child who sometimes finds it difficult to concentrate during class, and has some difficulties in reading and writing. However, in the studied laboratory setting, he was a crucial member of the group, since he spawned opposing predictions - that in the studied case turned out to be correct - and took initiatives to create instant inquiry investigation, driven by his genuine curiosity. Another aspect is the potential impact of the aesthetic experience of interacting with the IR cameras, which may appeal to different children to varying degrees. Once again, Stefan expresses particularly strong positive emotions in relation to the "cool" multi-colour images displayed on the screen. Nevertheless, a less encouraging characteristic of the exercise was that the two girls took on a more passive role in relation to the interaction with the IR camera, which tended to be dominated by the three boys throughout the exercise. Albeit so, this did not hinder Stina from fighting for attention and convincing the group to carry out her instant inquiry event of placing the pencil in water by the end of the exercise. Still, less assertive pupils might have had difficulties taking full advantage of the collaborative exercises.

Although the task of investigating the temperature of the mug and the cup was given to the pupils as part of the exercise, their interaction is characterised by engagement in inquiry, and the pupils taking ownership of their own learning (Enghag and Niedderer 2008). This applies to the sustained observation of the two objects throughout the exercise - our previous experience is that older students merely seek to confirm that the plastic cup gets warmer than the coffee mug, and then leave it at that - but in particular also to the emergent instances of instant inquiry. This observation leads to the question: What are the inquiry empowering aspects of the exercise in this instructional setting? First, we would claim that the IR imaging technology brings with it immediate appeal and intuition. With respect to the domain of thermal phenomena, an IR camera offers disciplinary affordances (Fredlund et al. 2012), and invites pupils to actively engage in 'what-if' investigations. Second, the task at hand was moderately challenging for the particular age group. If the task had been conceived as easy, the pupils would have agreed on the answer beforehand, and merely used the experiment to confirm it within seconds. In turn, a very difficult task leads to confusion about what to do and how to interpret the outcome. In this case, the pupils came up with different predictions beforehand, which generated a degree of tension and interest in what would actually occur. 
The task of developing teaching activities that are suitable for a certain age and knowledge level or even a particular group of students, is central to any teaching intervention. Finally, we think that the peer-to-peer interaction and the scaffolding provided by the researcher were crucial in bringing about the productive inquiry. It is the multitude of predictions and initiatives from the different participants that created the inquisitive spirit of the group. The researcher $(\mathrm{JH})$, in his capacity as facilitator, played an important role in directing the attention of the group to particular events or utterances from the children, such as Stefan's prediction that the water would get colder after the pencil is placed in it. Similarly, JH gave sanction to individual initiatives of instant inquiry, which were found to fit the overall learning objectives, even if they were not part of the explicit instructions, which otherwise could have been immediately abandoned in the face of peer scepticism, as was noted in the case when Stefan started to blow on the water surface.

When it comes to encouraging students to engage in evidence-based justifications, from this and previous studies (Haglund et al. 2012, 2014; Schönborn et al. 2014), we are convinced about the power of the POE approach to experimental work in whole class, or, as in this case, small-group settings. Pupils are more likely to engage personally in experiments if all of them are encouraged to provide their own predictions and explanations, and be prepared to hear and consider those of their peers, rather than only following a recipe of small tasks to perform one after another.

- What conceptions and conceptual challenges are expressed among a small group of fourth-graders in a laboratory exercise on heat by use of IR cameras?

A lasting impression of the pupils' interaction with the laboratory task is the adequacy of the language they used in relation to the studied phenomena. What they expressed reveals that they have adopted the taught heat-flow model (Tiberghien 1985; Linn and Eylon 2011; Arnold and Millar 1996; Rosebery et al. 2010), where heat is seen as flowing from warmer to colder objects. The model may have helped them to engage central concepts such as heat conduction, insulation and temperature, in understanding heating and cooling processes. Herein, Stefan's recognition that the surrounding water ought to get colder when the submerged pencil gets warmer is probably an example of the most advanced level of understanding and application of the model in the exercise.

When it comes to particular concepts, heat is conceived by the pupils as a substance-like entity that can be "held" within a coffee mug, or get "sucked up" by a pencil. This reflects an understanding of heat as an extensive quantity and of a transmission mechanism of heat conduction, which otherwise has been found only among pupils at least two years older than those in the current study (Howe 1998; Piaget and Garcia 1977).

In turn, temperature was seen as a level on a scale, particularly in the context of temperature changes, as expressed in the temperature "rising" and "falling". This is particularly interesting given the fact that there is no moving vertical scale on the IR camera, as is the case with a traditional liquid thermometer. There is a continuum-based colour key to the right on the IR camera screen where higher temperatures are coded as hues of red at the top, while lower temperatures are hues of blue below, but this does not move vertically. Rather, we think that the pupils have adopted this feature from scientific and everyday language (just think of the expressions involving "low" and "high" temperatures in the preceding sentences).

Even though the pupils exhibited an impressive grasp of the heat-flow model in this context, they were also confronted with conceptual challenges, as obtained during the prediction phase of the exercise. Initially, four of them predicted that the coffee mug would get warmer 
than the plastic cup, which later turned out not to be the actual outcome. As we have seen, the fact that there were different predictions beforehand contributed to the dynamics of the dialogue, but nevertheless, the pupils' erroneous expectations of what would occur point towards some kind of conceptual challenge. One factor influencing the idea that the coffee mug would get warmer may be that it is associated with heat through its function, as opposed to the plastic cup. It is maybe vaguely seen as 'better' at dealing with any matters pertaining to the idea of heat. In addition, at the start of the experiment, it was slightly warmer than the plastic cup. Second, as mentioned, Jonas conceives of the coffee mug as an ideal insulator, which completely prevents heat exchange through its walls.

\section{Educational Implications}

At one level, we see the study on the presented teaching sequence as providing evidence that pupils as young as 9-11 years old can be introduced to thermal phenomena by means of IR cameras. Astonishingly, we found the children to embrace the technology within minutes. There were virtually no challenges in interpreting the IR imagery, and they used the device to engage in sustained observation and instant inquiry.

Still, we have to raise the question: Why did the pupils in the present study adopt the heatflow model so successfully?

First, we think that one central factor was the explicit teaching of the heat-flow model preceding the small-group exercises. In comparison, in line with Erickson (1985), when asked to interact with IR cameras without the introduction of a heat-flow model, we have found $7^{\text {th }}$ graders to be reluctant to use heat as a noun, but prefer to talk of a warm object 'heating' another object, or focusing heavily on the temperature changes when touching a wooden and a metal object with their hands (Schönborn et al. 2014).

Second, the introduction of the IR camera itself provided rich and stimulating opportunities for seeing heat conduction in terms of a heat flow, engaging in instant inquiry into the change of the temperature of a water surface or a pencil, which otherwise would not have been possible to perform.

Third, there is the positive effect of the collaborative setting. The pupils in this group came up with diverging predictions very early, which made them realise that one can think of the same phenomenon in different ways, and focus their attention on finding out what really happens. In this case, the pupils came close to a consensus prediction before carrying out the experiment, which Howe and Tolmie (2003) have found to be advantageous in collaborative laboratory exercises, although involving a more active role for the pupils to design critical testing.

Fourth, a theme we have not touched upon much so far is the particularities of the studied activity, pouring hot water in cups. In contrast to the activity of touching metal and other materials at room temperature, this task did not involve having to explain why objects feel cold by means of a heat transfer from their bodies, which has been found to be challenging (Engel Clough and Driver 1985; Lewis and Linn 1994). This points to context sensitivity (e.g. Amin 2001; diSessa 1993; Gupta et al. 2010), in that the conceptions connected with the heat-flow model may be particularly attractive in relation to the cooling of warm water in cups, but not necessarily with other scenarios. Although not in focus in the present study, our impression is that the children had more difficulties with the task of touching wood and metal, than with the cups. One conclusion could be that the cup exercise might be introduced at an earlier stage than activities that have been found to require a more robust understanding. 
As another reflection, we are aware that the taught heat-flow model does not represent the current understanding of heat in science. However, in line with other proponents of heat-flow models (e.g. Linn and Eylon 2011), we see this macroscopic approach to disambiguating temperature and heat to be a useful stepping stone for the age group, and for yet another couple of years during their education. As mentioned, children of 12-13 years of age rarely spontaneously employ particle interactions in accounting for thermal phenomena (Shayer and Wylam 1981). In our view, grasping heat as an emergent phenomenon (Chi 2005) or in terms of particle interaction would be a challenge to be left to higher educational levels than in the present study.

Furthermore, the introduction of several complementary models of thermal phenomena at different educational stages emphasises that every single model involves simplification and idealisation, and that each will highlight certain aspects while playing down others (Gilbert 2004). In particular, since IR cameras provide predominately macroscopic disciplinary affordances (Fredlund et al. 2012), this technology is of limited value in the teaching of a particle interaction model of thermal phenomena. Here, instead we find other technology more attractive, such as particle interaction simulations (Wiser and Amin 2001; Perkins et al. 2006; Xie and Tinker 2006), which is another approach to make the invisible visible. Recently, molecular interaction software has been incorporated also into the Knowledge Integration framework (Chang and Linn 2013; Xie and Tinker 2006), which for a long time relied on macroscopic approaches.

Given the above, how far can these findings be transferred to other groups of pupils or to traditional teaching practice in schools, as opposed to the current research setting? First, we would have to offer a word of caution. Following Geertz (1973, p. 25) on small scale, interpretive practices in ethnographic studies: "What generality it contrives to achieve grows out of the delicacy of its distinctions, not the sweep of its abstractions." In this spirit, we found the notions of sustained observation and instant inquiry useful to describe the pupil interaction in this exercise, but can only hope that they might apply elsewhere.

Similarly, these pupils adopted the heat-flow model in this exercise, but, as mentioned, that is no guarantee that this would occur with another group in similar circumstances, or with the same group in other circumstances. In fact, as related in the method description, we chose to study this particular group of children in detail because of the level of engagement noted in their inquiry and dialogue.

Furthermore, even though the study was carried out in a classroom environment and framed within the regular teaching of the two classes, some conditions would not apply to everyday teaching. With the three researchers, the regular teacher of the class and a teaching assistant, we constituted five adults all focused on the four days of study. This enabled us to each follow one group of pupils during the small-group exercises, such as the one analysed here, which presented multiple possible scaffolding opportunities, to an extent that is rare (and unrealistic) in most contemporary classrooms.

If implemented as part of regular teaching, teachers would have to alternate between the groups or carry out more exercises as demonstrations, which has been found to work well when adopting a POE approach (White and Gunstone 1992). In addition, given the oftenstrained budgets of schools, acquiring two or four IR cameras may still be an economically daunting prospect. It is a matter of conviction that the technology can go beyond the "wow factor" (Chandler 2009) of innovation, in contributing fruitfully to students' learning, and believing that the potential benefits outweigh the costs. Newer and cheaper options, such as the currently available smart-phone FLIR ONE or Seek Thermal add-on accessories, will speak in favour of such development. 
In conclusion, contributing to findings within the Knowledge Integration framework (Linn and Eylon 2011) and adhering to White and Gunstone's (1992) approaches to probing students' understanding, the present study is an example of how we might take advantage of the three projected trends in science education mapped out initially: adopt novel visualization technology; take full advantage of the social setting, and; introduce age-appropriate scientific models to structure students' conceptual understanding.

\section{References}

Amin, T. G. (2001). A cognitive linguistics approach to the layperson's understanding of thermal phenomena. In A. Cienki, B. Luka, \& M. Smith (Eds.), Conceptual and discourse factors in linguistic structure (pp. 27-44). Stanford, CA: CSLI Publications.

Arnold, M., \& Millar, R. (1996). Learning the scientific "story": A case study in the teaching and learning of elementary thermodynamics. Science Education, 80(3), 249-281.

Atkins, L. J., Velez, L., Goudy, D., \& Dunbar, K. (2009). The unintended effects of interactive objects and labels in the science museum. Science Education, 93(1), 161184.

Brunsell, E., \& Horejsi, M. (2010). Science 2.0: Instant inquiry. The Science Teacher, 77(8), 10.

Cabello, R., Navarro-Esbrí, J., Llopis, R., \& Torrella, E. (2006). Infrared thermography as a useful tool to improve learning in heat transfer related subjects. International Journal of Engineering Education, 22(2), 373-380.

Cazzaniga, L., Giliberti, M., \& Ludwig, N. The use of infrared thermography to create a "bridge" connecting Physics in the lab to Physics of building. In A. Lindell, A.-L. Kähkönen, \& J. Viiri (Eds.), GIREP-EPEC, Jyväskylä, Finland, 1-5 August, 2011 (pp. 13-18): University of Jyväskylä

Chandler, P. (2009). Dynamic visualisations and hypermedia: Beyond the "wow" factor. Computers in Human Behavior, 25(2), 389-392.

Chang, H.-Y., \& Linn, M. C. (2013). Scaffolding learning from molecular visualizations. Journal of Research in Science Teaching, 50(7), 858-886.

Chi, M. T. H. (2005). Commonsense conceptions of emergent processes: Why some misconceptions are robust. Journal of the Learning Sciences, 14(2), 161-199.

Cobb, P., Confrey, J., diSessa, A., Lehrer, R., \& Schauble, L. (2003). Design experiments in educational research. Educational Researcher, 32(1), 9-13.

Creswell, J. (1997). Creating worlds, constructing meaning: The Scottish storyline method (Teacher to Teacher Series). Portsmouth, NH: Heinemann.

Derry, S. J., Pea, R. D., Barron, B., Engle, R. A., Erickson, F., Goldman, R., et al. (2010). Conducting video research in the learning sciences: Guidance on selection, analysis, technology, and ethics. Journal of the Learning Sciences, 19(1), 3-53.

Dewey, J. (1938/1997). Experience and education. New York, NY: Simon \& Schuster.

Dexter, A. (2013). Seeing the unseen: An investigation of heat transfer using infrared thermography and LabVIEW. Tufts University,

diSessa, A. A. (1993). Toward an epistemology of physics. Cognition and Instruction, 10(23), $105-225$.

diSessa, A. A. (2014). The construction of causal schemes: Learning mechanisms at the knowledge level. Cognitive Science, 38(5), 795-850.

Duit, R. (1984). Learning the energy concept in school - empirical results from the Philippines and West Germany. Physics Education, 19(2), 59-66.

Engel Clough, E., \& Driver, R. (1985). Secondary students' conceptions of the conduction of heat: bringing together scientific and personal views. Physics Education, 20(4), 176182. 
Enghag, M., \& Niedderer, H. (2008). Two dimensions of student ownership of learning during small-group work in physics. International Journal of Science and Mathematics Education, 6(4), 629-653.

Erickson, G. L. (1985). Heat and temperature. Part A: An overview of pupils' ideas. In R. Driver, E. Guesne, \& A. Tiberghien (Eds.), Children's ideas in science (pp. 55-66). Milton Keynes, UK: Open University Press.

Fredlund, T., Airey, J., \& Linder, C. (2012). Exploring the role of physics representations: an illustrative example from students sharing knowledge about refraction. European Journal of Physics, 33(3), 657.

Geertz, C. (1973). Thick description: Toward an interpretative theory of culture. In C. Geertz (Ed.), The interpretation of cultures: Selected essays (pp. 3-30). New York, NY: Basic Books.

Gilbert, J. K. (2004). Models and modelling: routes to more authentic science education. International Journal of Science and Mathematics Education, 2(2), 115-130.

Gupta, A., Hammer, D., \& Redish, E. F. (2010). The case for dynamic models of learners' ontologies in physics. Journal of the Learning Sciences, 19(3), 285-321.

Haglund, J., Jeppsson, F., \& Andersson, J. (2012). Young children's analogical reasoning in science domains. Science Education, 96(4), 725-756.

Haglund, J., Jeppsson, F., \& Andersson, J. (2014). Primary school children's ideas of mixing and of heat as expressed in a classroom setting. Journal of Baltic Science Education, 13(5), 726-739.

Hake, R. R. (1998). Interactive-engagement versus traditional methods: A six-thousandstudent survey of mechanics test data for introductory physics courses. American Journal of Physics, 66(1), 64-74.

Helldén, G. (2005). Exploring understandings and responses to science: A program of longitudinal studies. Research in Science Education, 35(1), 99-122.

Hmelo-Silver, C. E., Duncan, R. G., \& Chinn, C. A. (2007). Scaffolding and achievement in problem-based and inquiry learning: A response to Kirschner, Sweller, and Clark (2006). Educational Psychologist, 42(2), 99-107.

Hofstein, A., \& Lunetta, V. N. (1982). The role of the laboratory in science teaching: Neglected aspects of research. Review of Educational Research, 52(2), 201-217.

Hofstein, A., \& Lunetta, V. N. (2004). The laboratory in science education: Foundations for the twenty-first century. Science Education, 88(1), 28-54.

Howe, C. (1998). Conceptual structure in childhood and adolescence: The case of everyday physics. London, UK: Routledge.

Howe, C., \& Tolmie, A. (2003). Group work in primary school science: discussion, consensus and guidance from experts. International Journal of Educational Research, 39(1-2), 51-72.

Howe, C., Tolmie, A., Greer, K., \& Mackenzie, M. (1995). Peer collaboration and conceptual growth in physics: Task influences on children's understanding of heating and cooling. Cognition and Instruction, 13(4), 483-503.

Johnson, D. W., Maruyama, G., Johnson, R., Nelson, D., \& Skon, L. (1981). Effects of cooperative, competitive, and individualistic goal structures on achievement: A metaanalysis. Psychological Bulletin, 89(1), 47-62.

Kirschner, P. A., Sweller, J., \& Clark, R. E. (2006). Why minimal guidance during instruction does not work: An analysis of the failure of constructivist, discovery, problem-based, experiential, and inquiry-based teaching. Educational Psychologist, 41(2), 75-86.

Klahr, D., Zimmerman, C., \& Jirout, J. (2011). Educational interventions to advance children’s scientific thinking. Science, 333(6045), 971-975. 
Kröger, J. (2012). Entwicklung von Experimenten zur Einführung der Energieentwertung und Energieerhaltung im Physikunterricht der Mittelstufe (Development of experiments for the introduction of energy degradation and energy conservation in secondary physics teaching). Christian-Albrechts-Univerität Kiel,

Lehrer, R., \& Schauble, L. (2006). Cultivating model-based reasoning in science education. In R. K. Sawyer (Ed.), The Cambridge handbook of the learning sciences (pp. 371388). Cambridge, UK: Cambridge University Press.

Lewis, E. L., \& Linn, M. C. (1994). Heat energy and temperature concepts of adolescents, adults, and experts: implications for curricular improvements. Journal of Research in Science Teaching, 31(6), 657-678.

Linn, M. C. (2003). Technology and science education: Starting points, research programs, and trends. International Journal of Science Education, 25(6), 727-758.

Linn, M. C., \& Eylon, B.-S. (2011). Science learning and instruction: taking advantage of technology to promote knowledge integration. New York, NY: Routledge.

Mach, E. (1896/1986). Principles of the theory of heat. Dordrecht, the Netherlands: Reidel.

Möllmann, K.-P., \& Vollmer, M. (2007). Infrared thermal imaging as a tool in university physics education. European Journal of Physics, 28(3), S37-S50.

Naghedolfeizi, M., Arora, S., \& Glover, J. E. (2011). Visualizing conductive and convective heat transfer using thermographic techniques. Paper presented at the 41st ASEE/IEEE Frontiers in Education Conference, October 12-15, Rapid City, SD,

Okebukola, P. A., \& Ogunniyi, M. B. (1984). Cooperative, competitive, and individualistic science laboratory interaction patterns-effects on students' achievement and acquisition of practical skills. Journal of Research in Science Teaching, 21(9), 875884.

Olson, S., \& Loucks-Horsely, S. (2000). Inquiry and the national science education standards: A guide for teaching and learning. Washington, DC: National Academy Press.

Osborne, J., Simon, S., \& Collins, S. (2003). Attitudes towards science: A review of the literature and its implications. International Journal of Science Education, 25(9), 1049-1079.

Pendrill, A.-M., Karlsteen, M., \& Rödjegård, H. (2012). Stopping a roller coaster train. Physics Education, 47(6), 728-735.

Perkins, K., Adams, W., Dubson, M., Finkelstein, N., Reid, S., Wieman, C., et al. (2006). PhET: Interactive simulations for teaching and learning physics. The Physics Teacher, 44(1), 18-23.

Piaget, J. (1929). The child's conception of the world. London, UK: Routledge.

Piaget, J. (1930). The child's conception of physical causality. London, UK: Kegan Paul.

Piaget, J. (1932). The moral judgement of the child. London, UK: Kegan Paul.

Piaget, J., \& Garcia, R. (1977). Understanding causality. New York, NY: The Norton Library.

Posner, G. J., Strike, K. A., Hewson, P. W., \& Gertzog, W. A. (1982). Accommodation of a scientific conception: Toward a theory of conceptual change. Science Education, 66(2), 211-227.

Rocard, M., Csermely, P., Jorde, D., Lenzen, D., Walberg-Henriksson, H., \& Hemmo, V. (2007). Science education now: A renewed pedagogy for the future of Europe. Luxemburg: Office for Official Publications of the European Communities.

Rosebery, A. S., Ogonowski, M., DiSchino, M., \& Warren, B. (2010). "The coat traps all your body heat": Heterogeneity as fundamental to learning. Journal of the Learning Sciences, 19(3), 322-357. 
Schönborn, K. J., Haglund, J., \& Xie, C. (2014). Pupils’ early explorations of thermoimaging to interpret heat and temperature. Journal of Baltic Science Education, 13(1), 118132.

Shayer, M., \& Wylam, H. (1981). The development of the concepts of heat and temperature in 10-13 year-olds. Journal of Research in Science Teaching, 18(5), 419-434.

Short, D. B. (2010). Thermal imaging in the science classroom. School Science Review, 94(346), 75-78.

Sjøberg, S., \& Schreiner, C. (2005). How do learners in different cultures relate to science and technology? Results and perspectives from the project ROSE (The Relevance of Science Education). Asia-Pacific Forum on Science Learning and Teaching, 6(2), 117.

Skolverket (2011). Curriculum for the compulsory school, preschool class and the recreational centre 2011. Stockholm, Sweden: Swedish National Agency for Education.

Tiberghien, A. (1985). Heat and temperature. Part B: The development of ideas with teaching. In R. Driver, E. Guesne, \& A. Tiberghien (Eds.), Children's ideas in science (pp. 67-84). Milton Keynes, UK: Open University Press.

Tobin, K. (1990). Research on science laboratory activities: In pursuit of better questions and answers to improve learning. School Science and Mathematics, 90(5), 403-418.

Tytler, R., \& Peterson, S. (2005). A longitudinal study of children's developing knowledge and reasoning in science. Research in Science Education, 35(1), 63-98.

White, R., \& Gunstone, R. (1992). Probing understanding. London, UK: The Falmer Press.

Wiser, M., \& Amin, T. G. (2001). "Is heat hot?” Inducing conceptual change by integrating everyday and scientific perspectives on thermal phenomena. Learning and Instruction, 11(4-5), 331-355.

Vollmer, M., \& Möllmann, K.-P. (2010). Infrared thermal imaging: fundamentals, research and applications. Weinheim, Germany: Wiley-VCH.

Vollmer, M., Möllmann, K.-P., Pinno, F., \& Karstädt, D. (2001). There is more to see than eyes can detect - Visualization of energy transfer processes and the laws of radiation for physics education. The Physics Teacher, 39(6), 371-376.

Wood, D., Bruner, J. S., \& Ross, G. (1976). The role of tutoring in problem solving. Journal of Child Psychology and Psychiatry, 17(2), 89-100.

Vygotsky, L. S. (1962). Thought and language. Cambridge, MA: MIT Press.

Vygotsky, L. S. (1978). Mind in society: The development of higher psychological processes. Cambridge, MA: Harvard University Press.

Xie, C. (2011). Visualizing chemistry with infrared imaging. Journal of Chemical Education, 88(7), 881-885.

Xie, C. (2014). The Concord Consortium. Infrared Tube. http://energy.concord.org/ir. Accessed 16 May 2014.

Xie, C., \& Hazzard, E. (2011). Infrared imaging for inquiry-based learning. The Physics Teacher, 49(6), 368-372.

Xie, C., \& Tinker, R. (2006). Molecular dynamics simulations of chemical reactions for use in education. Journal of Chemical Education, 83(1), 77-83. 